\title{
Zymomonas mobilis: um microrganismo promissor para a fermentação alcoólica
}

\section{Zymomonas mobilis: a promising microrganism for alcoholic fermentation}

\author{
Fernanda Maria Pagane Guereschi Ernandes ${ }^{1 *}$; Crispin Humberto Garcia-Cruz ${ }^{2}$
}

\section{Resumo}

Em vários países têm sido realizados estudos de fermentação que incluem o uso de bactérias em vez de leveduras para reduzir o tempo de fermentação alcoólica. No Brasil, toda a produção industrial de álcool é realizada utilizando leveduras como microrganismo da fermentação e pouco se conhece de outros microrganismos que produzam álcool a nível industrial. Em virtude da situação de destaque em que se encontra o Brasil a nível mundial no setor energético, algumas instituições vêm selecionando microrganismos mais eficientes no processo de produção de álcool. As bactérias alcoólicas da espécie Zymomonas mobilis apresentam atributos tecnológicos que potencializam o seu emprego na fermentação alcoólica em escala industrial, pois possui habilidades promissoras de transformar açúcares em etanol e gás carbônico, em condições comparáveis àquelas exigidas pelas leveduras. Zymomonas mobilis é uma bactéria única dentro do mundo microbiano, com crescimento, produção de energia e resposta às condições de cultura extremamente peculiares, causando um grande interesse no mundo científico, biotecnológico e industrial. A habilidade da bactéria em acoplar e desacoplar a produção de energia a favor da formação do produto, responder à manipulação física e química do ambiente, bem como sua limitada formação de produtos tornam-a um microrganismo ideal para o estudo e desenvolvimento de processos microbianos para a produção de etanol.

Palavras-chave: Zymomonas mobilis, etanol, fermentação alcoólica, cana-de-açúcar

\begin{abstract}
In many countries, fermentation studies regarding the use of bacteria instead of yeasts to reduce the period of alcoholic fermentation have been carried out. In Brazil, all the industrial alcohol production is carried out by yeasts as fermentation microorganisms and little is known about other microorganisms with potential to produce alcohol industrially. Brazil stands out in the energy sector worldwide and thus some institutions have been selecting microorganisms which are more efficient in the alcohol production process. Alcoholic bacteria from species Zymomonas mobilis present technological characteristics with potential to be used for alcoholic fermentation at industrial scale, since it exhibits promising abilities to transform sugars into alcohol and carbon dioxide, at conditions similar to the ones required by yeasts. Zymomonas mobilis is a unique bacteria among the microbial world, with peculiar growth, energy production and response to culture conditions, causing a great interest in scientific, biotechnological and industrial fields. The bacteria's ability to make possible energy production in favor of product
\end{abstract}

\footnotetext{
1 Farmacêutica, Mestre em Ciências de Alimentos pela Universidade Estadual Paulista (UNESP) e atualmente é doutoranda no Curso de Engenharia de Alimentos, Área de concentração Ciência e Tecnologia de Alimentos, Instituto de Biociências, Letras e Ciências Exatas, Universidade Estadual Paulista (UNESP), Campus de São José do Rio Preto. E-mail: fernandaer@ig.com.br

2 Professor Dr. do Departamento de Engenharia e Tecnologia de Alimentos, Instituto de Biociências, Letras e Ciências Exatas, Curso Engenharia de Alimentos, Universidade Estadual Paulista (UNESP), Campus de São José do Rio Preto. E-mail: crispin@ ibilce.unesp.br

* Autor para correspondência
} 
formation, respond to physical and chemical environmental manipulation as well as its limited product formation make it an ideal microorganism for the study and development of microbial processes for ethanol production.

Key words: Zymomonas mobilis, ethanol, alcoholic fermentation, sugarcane

\section{Considerações Gerais}

$\mathrm{Na}$ fermentação alcoólica, as leveduras são os microrganismos comumente utilizados a nível industrial. Contudo, nos últimos 15 anos, a bactéria Zymomonas mobilis vem despertando muito interesse pelo seu potencial na produção de etanol, produzindo cerca de 1,9 mol de etanol por mol de glicose, com velocidade três a quatro vezes maior que Saccharomyces cereviseae. Apesar das vantagens apresentadas por Zymomonas mobilis perante as leveduras (fermentações mais rápidas com maior rendimento em etanol, condições de crescimento mais simples, maior taxa específica de produção de álcool e consumo de substrato, maior tolerância a elevadas temperaturas, concentração de açúcar e etanol) o rendimento fermentativo diminui quando se utiliza sacarose como carboidrato para a fermentação. Isto é devido, segundo alguns autores, à formação de subprodutos como levana e sorbitol.

Nem sempre têm sido consideradas as condições de cultivo e os processos fermentativos para determinar os parâmetros que um determinado microrganismo necessita para uma ótima síntese dos produtos de fermentação. Na literatura, quando disponíveis, os dados publicados demonstram que a temperatura e o $\mathrm{pH}$ ideais usados para a fermentação com Zymomonas mobilis dependerão do que se deseja maximizar no final do processo. A influência do $\mathrm{pH}$, da temperatura e a composição do meio de fermentação estudadas com Zymomonas mobilis, são manipulados com o objetivo de aumentar a produção de etanol e reduzir a formação de subprodutos (levana e sorbitol).

Devido a crise do petróleo, a partir de 1973, houve um grande interesse na busca de recursos energéticos renováveis, assim como em encontrar fontes de recursos orgânicos capazes de substituir os atuais produtos petroquímicos. Desta forma, por um lado realizaram-se esforços para melhorar a rentabilidade dos processos de obtenção de bioálcool, e por outro tratou-se de substituir os processos do tipo químico por outros do tipo biológico. A partir da década de 80 , estes estudos perderam impulso durante um certo tempo; contudo, a consciência de que os combustíveis fósseis vão se esgotar e que é necessário utilizar tecnologias menos contaminantes, tem feito renascer o interesse nestes processos biológicos.

A presente proposta tem como objetivo apresentar uma extensa revisão bibliográfica para obter mais informações sobre o histórico e as características fisiológicas de Zymomonas mobilis, e com isto, regular a síntese de etanol e ainda, otimizar os processos tecnológicos de sua produção, tornando-a um microrganismo promissor para a fermentação alcoólica.

\section{Levantamento Bibliográfico}

\section{A bactéria Zymomonas mobilis}

\section{Histórico do microrganismo}

$\mathrm{O}$ uso de microrganismos com a finalidade de obter produtos que venham beneficiar e melhorar o estilo de vida do homem são parte da civilização desde o início dos tempos. O "aguamiel" (seiva fermentada naturalmente por Zymomonas mobilis) foi utilizado pelos astecas na prevenção e no tratamento de infecções intestinais, ainda quando não se conhecia o efeito benéfico dos microrganismos. Em 1911, Barker e Hillier apud Swings e De Ley (1977) foram os primeiros a estudar a bactéria responsável pela deterioração do flavour de bebidas fermentadas, sendo a eles atribuída a real descoberta desse gênero. Estes, como não atribuíram um 
binômio latino ao nome de Zymomonas mobilis, em 1928, foi creditada a Lindner apud Swings e De Ley (1977), a descoberta dessa bactéria, por ocasião do seu isolamento no México, a partir da seiva fermentada de Agave atroveriens, o qual constitui uma bebida regional muito popular chamada "pulque" (GONÇALVES DE LIMA et al., 1970).

Logo após o isolamento da bactéria Zymomonas mobilis, em 1931, Lindner, estudando as propriedades antagonistas dessa bactéria verificou, após ingerir o filtrado, ótimos resultados quando o mesmo era utilizado no tratamento de certas infecções entéricas e deu o nome a ela de Termobacterium mobile sendo muito semelhante à de Barker e Hillier (FALCÃO DE MORAIS, 1983). Em 1936, Kluyver e Van Niel reconhecem-na como gênero Zymomonas, considerando uma só espécie Zymomonas mobilis com duas subespécies: Zymomonas mobilis subsp. mobilis e a Zymomonas mobilis subsp. pomacii (SWINGS; DE LEY, 1977, FALCÃO DE MORAIS, 1983).

A década de 70 caracterizou-se por apresentar diversos esforços no sentido de melhorar e buscar novas fontes para a produção de etanol. Dentro deste contexto, a bactéria Zymomonas mobilis revelou-se um microrganismo promissor. Durante a fermentação da sacarose para sua conversão em etanol, no entanto, surgiu como uma das razões do baixo rendimento, um polissacarídeo, a princípio de alto peso molecular, formado a partir da hidrólise da sacarose, denominado então de levana (JEREZ, 1993; ERNANDES, 2006). Segundo Garcia-Cruz (1997), a levana é produzida a partir da sacarose e não da glicose e frutose ou mistura de ambas e, sendo um anidofructosilfructosídio solúvel em água, pode ser também chamado de polifrutana pelo fato de ser constituído de moléculas de frutose. Na indústria de alimentos, a levana tem vários usos potenciais: agente espessante, fixador de cores e sabores e em produtos dietéticos (YUN, 1996). Além disso, sua hidrólise produz frutose que tem poder adoçante superior à sacarose (ERNANDES; GARCIA-CRUZ, 2005).

A ocorrência da bactéria Zymomonas mobilis foi verificada em várias partes do mundo e em diversos meios açucarados (DADDS; MARTIN, 1973; SWINGS; DE LEY, 1977). Na Europa, em vinhos de maçãs e de pêras (MILLIS, 1956), em polpa de maçã (CARR; PASSMORE, 1971) e como contaminante em indústrias de cerveja (DADDS; MARTIN, 1973). No México, na fermentação da seiva do agave (CARR, 1974); na África, Ásia e Américas, fermentando vinhos de seiva de palmas diversas (DADDS; MARTIN, 1973).

No Brasil, especificamente em Pernambuco (nordeste brasileiro), Gonçalves de Lima isolou diversas linhagens de Zymomonas a partir de caldo de cana-de-açúcar fermentado, bebida popularmente conhecida como "caldo de cana picado", e que através de estudos taxonômicos foi denominada de Zymomonas mobilis variedade recifensis (GONÇALVES DE LIMA et al., 1970; FALCÃO DE MORAIS, 1983; FALCÃO DE MORAIS et al., 1993).

Desde a década de 50, o Departamento de Antibióticos daUniversidadeFederal de Pernambuco (DAUFPE) vem estudando a atividade antagonista de Zymomonas mobilis em infecções entéricas causadas por Salmonella, Shigella e Escherichia coli. Os resultados obtidos indicaram o uso desta bactéria como agente terapêutico no combate a enterocolite e cistite, sendo obtida a regressão dos sintomas em todos os casos (GONÇALVES DE LIMA et al., 1970).

Swings e De Ley (1977) descrevem em seu trabalho as diferentes linhagens de Zymomonas mobilis encontradas em vários países e o pesquisador responsável pelo seu isolamento (Tabela 1). 
Tabela 1. Diferentes linhagens de Zymomonas mobilis encontradas em vários países e o pesquisador responsável pelo seu isolamento.

\begin{tabular}{|c|c|c|c|c|c|}
\hline Linhagem & $\mathrm{N}^{\mathrm{o}}$ de linhagem & Fonte & Local & $\begin{array}{c}\text { Data de } \\
\text { Publicação }\end{array}$ & Isolado por \\
\hline Zymomonas mobilis & $\begin{array}{c}\text { ATCC } 10988 \\
\text { NCIB } 8938 \\
\text { NRRL B-806 }\end{array}$ & Agave & México & 1924 & Lindner \\
\hline $\begin{array}{l}\text { Zymomonas mobilis } \\
\text { subsp. pomaceae }\end{array}$ & $\begin{array}{l}\text { NCIB } 11200 \\
\text { ATCC } 29192\end{array}$ & Cidra & Bristol, U.K. & antes 1951 & $\begin{array}{l}\text { Barker e } \\
\text { Kluyver }\end{array}$ \\
\hline $\begin{array}{l}\text { Zymomonas mobilis } \\
\text { subsp. pomaceae }\end{array}$ & 1 & Cidra & Bristol, U.K. & 1950 & Millis \\
\hline $\begin{array}{l}\text { Zymomonas mobilis } \\
\text { subsp. pomaceae }\end{array}$ & 2 & Cidra & Bristol, U.K. & 1950 & Millis \\
\hline Zymomonas mobilis & AG 11 & Agave & México & 1950 & $\begin{array}{c}\text { Gonçalves de } \\
\text { Lima et al. }\end{array}$ \\
\hline $\begin{array}{l}\text { Zymomonas mobilis } \\
\text { subsp. pomaceae }\end{array}$ & $\begin{array}{c}\text { NCIB } 8777 \\
\text { ATCC } 29192\end{array}$ & Agave & Bristol, U.K. & antes 1951 & Carr \\
\hline Zymomonas anaerobia & D-364 & Cerveja & Bristol, U.K. & 1966 & Shimwell \\
\hline Zymomonas mobilis & $\begin{array}{c}\text { VP1, VP2, VP3, } \\
\text { VP4 }\end{array}$ & Elaeis sap & $\begin{array}{l}\text { Kinshasa, } \\
\text { Zaire }\end{array}$ & 1969 & Swings \\
\hline Zymomonas mobilis & 7.4 & Elaeis sap & $\begin{array}{l}\text { Kinshasa, } \\
\text { Zaire }\end{array}$ & 1969 & Swings \\
\hline Zymomonas mobilis & $\begin{array}{c}70.1,70.2,70.3 \\
70.7,70.8,70.9 \\
70.10,70.11 \\
70.12,70.14\end{array}$ & Elaeis sap & $\begin{array}{c}\text { Kinshasa, } \\
\text { Zaire }\end{array}$ & 1970 & Swings \\
\hline Zymomonas mobilis & $\mathrm{CP} 1, \mathrm{CP} 2, \mathrm{CP} 4$ & $\begin{array}{l}\text { caldo de } \\
\text { cana-de- } \\
\text { açúcar }\end{array}$ & Recife, Brasil & 1970 & $\begin{array}{c}\text { Gonçalves de } \\
\text { Lima et al. }\end{array}$ \\
\hline $\begin{array}{l}\text { Zymomonas mobilis var. } \\
\text { recifensis }\end{array}$ & $\mathrm{CP} 4$ & $\begin{array}{l}\text { caldo de } \\
\text { cana-de- } \\
\text { açúcar }\end{array}$ & Recife, Brasil & 1970 & $\begin{array}{c}\text { Gonçalves de } \\
\text { Lima et al. }\end{array}$ \\
\hline
\end{tabular}

Fonte: Swings e De Ley (1977). 
Características fisiológicas do microrganismo

A bactéria Zymomonas mobilis é Gram-negativa, não esporulante e móvel, anaeróbia facultativa, sendo que, algumas linhagens são obrigatoriamente anaeróbias. Morfologicamente, apresenta-se na forma de bastonete curto e grosso medindo de 2,0 a $6,0 \mu \mathrm{m}$ de comprimento e 1,0 a 1,4 $\mu \mathrm{m}$ de largura. Quando apresenta mobilidade, possui de um a quatro flagelos polares (FALCÃO DE MORAIS, 1983). São encontradas geralmente em pares, embora também apareçam isoladas. Possuem rotas catabólicas comparativamente simples e não tem a variedade de alternativas metabólicas encontradas em outros microrganismos. De forma a gerar energia suficiente para o crescimento, Zymomonas mobilis deve catabolizar substratos com altas taxas específicas de carbono, resultando em baixos rendimentos de biomassa pois a maior parte deste substrato é incorporado no catabolismo do produto final, o etanol (TOMA et al., 2003).

Em meios com altas concentrações de açúcar (melaço com mais de $15^{\circ}$ Brix), estas bactérias ocorrem como longos filamentos de extremidades dilatadas. Em meio sólido à base de glicose, as colônias apresentam-se lenticulares de bordas regulares, de coloração branca ou creme e com 1,0 a 2,0 $\mathrm{mm}$ de diâmetro após 2 dias de incubação a $30^{\circ} \mathrm{C}$ (SWINGS; DE LEY, 1977).

Açúcares fermentáveis com glicose, frutose e, em alguns casos, sacarose, são indispensáveis na composição do meio de cultura de Zymomonas mobilis. Esta fermenta glicose e frutose gerando quantidades praticamente equimolares de etanol e $\mathrm{CO}_{2}$, formando colônias de coloração branca ou creme.

A fermentação de 1 mol de glicose dá origem a 1,6 de etanol, 1,8 moles de $\mathrm{CO}_{2}$ e pequena quantidade de outros subprodutos com lactato, acetaldeído, ácido acético, glicerol, acetoína, dihidroxicetona, sorbitol, manitol, levana e ácido glicônico.

As condições ideais para o crescimento desta bactéria são intervalos de temperatura de 30 a $36^{\circ} \mathrm{C}$ e intervalos de $\mathrm{pH}$ entre 5 e 7. Cultivadas em meio complexo, podem converter $98 \%$ da glicose presente em etanol, $\mathrm{CO}_{2}$, lactato e outros, seguindo um balanço metabólico simples. Apenas $2 \%$ da glicose são utilizados para formar biomassa. As Tabelas 2 e 3 mostram a porcentagem de crescimento de linhagens de Zymomonas mobilis em diferentes valores de pH e temperatura de incubação, respectivamente (SWINGS; DE LEY, 1977).

Tabela 2. Porcentagem de crescimento de linhagens de Zymomonas mobilis em diferentes valores de $\mathrm{pH}$.

\begin{tabular}{cc}
\hline $\mathrm{pH}$ inicial & \% de crescimento de linhagens \\
\hline 3,05 & 0 \\
3,5 & 43 \\
3,7 & 71 \\
3,85 & 90 \\
5,7 & 100 \\
4,5 & 87 \\
8,0 & 0 \\
\hline
\end{tabular}

Fonte: Swings e De Ley (1977).

Tabela 3. Porcentagem de crescimento de linhagens de Zymomonas mobilis em diferentes valores de temperatura de incubação $\left({ }^{\circ} \mathrm{C}\right)$.

\begin{tabular}{cc}
\hline $\begin{array}{c}\text { Temperatura de } \\
\text { incubação }\left({ }^{\circ} \mathrm{C}\right)\end{array}$ & $\begin{array}{c}\text { \% de crescimento de } \\
\text { linhagens }\end{array}$ \\
\hline 30 & 100 \\
34 & 97 \\
36 & 97 \\
38 & 74 \\
40 & 5 \\
\hline
\end{tabular}

Fonte: Swings e De Ley (1977).

Na hidrólise da sacarose, ou de misturas de glicose e frutose, os subprodutos da formação de etanol são a levana e o sorbitol. A frutose, formada da hidrólise da sacarose, não é primariamente transportada para o interior das células, mas sim utilizada na formação de levana e frutooligômeros pela ação da enzima levanasacarase (LOOS et al., 1994).

A maioria das cepas requer ácido pantotênico, biotina e, ocasionalmente, alguns outros fatores 
de crescimento como vitamina $B_{12}$, riboflavina, tiamina, ácido lipóico e ácido fólico. Além disso, altas quantidades de extrato de levedura aumentam a produção de células, mas não necessariamente a produtividade de etanol, levana ou sorbitol (CROMIE; DOELLE, 1980).

Belaich e Senez (1965) estudaram o efeito de pantotenato no crescimento de Zymomonas mobilis e observaram que a limitação desta substância resulta na redução da velocidade específica de crescimento da bactéria. Os autores citam que o pantotenato é uma vitamina essencial à produção de etanol porque a bactéria não sintetiza pantotenato, mas necessita desta substância para produzir compostos orgânicos essenciais para o crescimento celular, produzindo, conseqüentemente, etanol.

Nas fermentações com Zymomonas mobilis em meio de cultivo contendo glicose, extrato de levedura, sulfato de amônio, fosfato de potássio e sulfato de magnésio, quando a glicose é exaurida, cessa-se a utilização da fonte inorgânica de nitrogênio $\left(\mathrm{NH}_{4}\right)$ e a bactéria começa a metabolizar os aminoácidos do meio como fonte de carbono, com liberação do nitrogênio na forma de amônia, resultando num aumento do $\mathrm{pH}$ do meio. Caso o meio de cultivo seja alimentado novamente com glicose o $\mathrm{pH}$ deste meio diminui gradualmente. Isto se deve a que o mecanismo que gera o potencial eletroquímico, e direciona o processo de transporte de entrada de glicose, opera via excreção de prótons com os produtos metabólicos por ação da enzima próton-translocante ATPase localizada na membrana celular (ISHIZAKI et al., 1994).

O metabolismo de açúcares de Zymomonas mobilis, ilustrado na Figura 1, aparece como uma "via metabólica" com algumas ramificações.
A sacarose é metabolizada a glicose e frutose pela ação das enzimas invertase (INV B) e levanasacarase (LEV U). As duas hexoses entram na célula via sistema de difusão facilitada (GLF) ou são convertidas pela GFOR (glicose-frutose oxirredutase), uma enzima contendo NADP (nicotinamida-adenina-dinucleotídeo-fosfato) que existe apenas na bactéria Zymomonas mobilis. A enzima GFOR madura está localizada no periplasma, oxida glicose a gliconolactona e reduz frutose a sorbitol. Gliconolactona é, então, convertida pela gliconolactonase (GL), outra enzima periplasmática, em ácido glicônico (gliconato). Ambas as enzimas são os principais constituintes do periplasma, formando aproximadamente 20 a $30 \%$ das proteínas deste compartimento. O ácido glicônico é consumido pelas células e pode ser completamente degradado (como um co-substrato) a etanol e ácido acético. O sorbitol é produzido para neutralizar o efeito prejudicial de estresse osmótico (SPRENGER, 1996).

Segundo Doelle et al. (1993), Zymomonas mobilis é uma bactéria única dentro do mundo microbiano, com crescimento, produção de energia e resposta às condições de cultura extremamente peculiares, causando um grande interesse no mundo científico, biotecnológico e industrial. Os autores afirmam que a habilidade da bactéria em acoplar e desacoplar a produção de energia a favor da formação do produto, responder à manipulação física e química do ambiente, bem como sua limitada formação de produtos tornam-a um microrganismo ideal para o estudo e desenvolvimento de processos microbianos. 


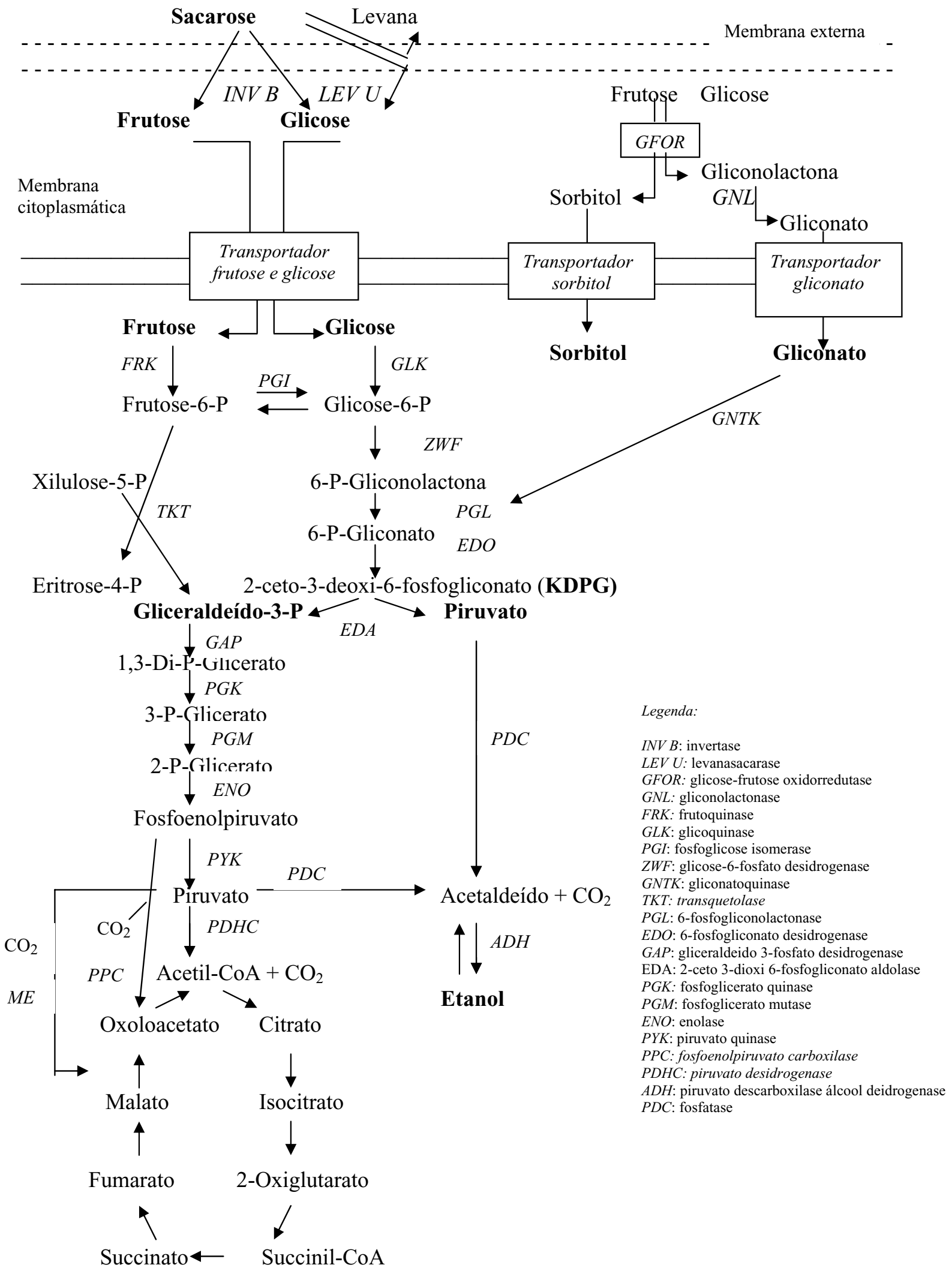

Figura 1. Metabolismo dos carboidratos em Zymomonas mobilis.

Fonte: Sprenger (1996). 
Produção de Etanol por Zymomonas Mobilis

O Brasil foi o primeiro país a adotar a bioenergia em larga escala com a implantação do Programa Nacional do Álcool (PROÁLCOOL) pelo decreto $\mathrm{n}^{\mathrm{o}} 76.593$ do Governo Federal em 14 de novembro de 1975. Este programa trouxe diversos benefícios, como o desenvolvimento rural e a criação de um combustível que colabora com a redução da poluição ambiental.

Quanto ao petróleo, devido a grande instabilidade dos preços e fornecimento, em virtude de forte dependência geopolítica, muitos países estão considerando razoável, e necessário, a curto e médio prazo, um constante investimento no estudo de formas, economicamente viáveis de obtenção de fontes renováveis de energia, com grande destaque para a produção de etanol. A fermentação alcoólica pode ser analisada através de duas maneiras:

Bioquímica: sob o ponto de vista bioquímico, o processo da fermentação alcoólica caracteriza-se como uma via catabólica, na qual há a degradação de moléculas de açúcar (glicose ou frutose), no interior da célula de microrganismos (leveduras ou bactérias), até a formação de etanol e $\mathrm{CO}_{2}$, havendo liberação de energia química e térmica. A glicólise é a via central do catabolismo da glicose, sendo que o piruvato é o produto final desse processo, o qual pode seguir diferentes vias metabólicas: fermentação alcoólica, láctea e respiração no ciclo de Krebs e cadeia respiratória (Figura 2).

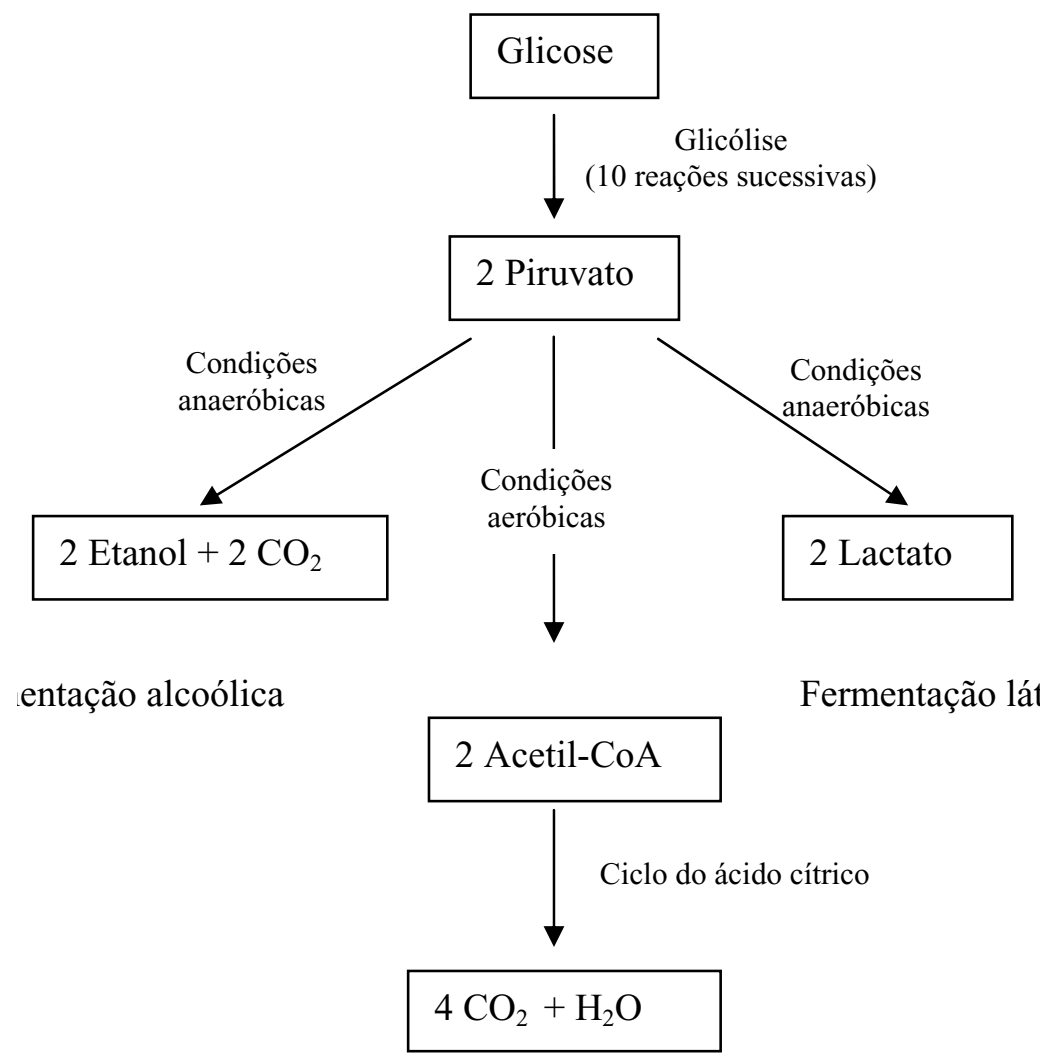

Figura 2. Catabolismo da glicose.

Fonte: Lehninger (2002). 
$\mathrm{Na}$ fermentação alcoólica, o piruvato é descarboxilado, formando acetaldeído e posteriormente reduzido a etanol. A equação da fermentação alcoólica apresenta-se da seguinte maneira:

$\mathrm{C}_{6} \mathrm{H}_{12} \mathrm{O}_{6}+2 \mathrm{P}_{\mathrm{i}}+2 \mathrm{ADP} \rightarrow 2 \mathrm{C}_{2} \mathrm{H}_{5} \mathrm{OH}+2 \mathrm{CO}_{2}+2 \mathrm{ATP}+2 \mathrm{H}_{2} \mathrm{O}$

Microbiológica: a fermentação é realizada por leveduras, embora alguns tipos de bactérias possam produzir álcool. Cerca de 500 espécies de leveduras são conhecidas pelo homem. Dentre elas, destacamse como produtoras de etanol, espécies do gênero Saccharomyces, Schizosaccharamyces, Pichia e outras. A espécie mais importante de levedura alcoólica é a Saccharomyces cerevisiae, que possui um largo espectro de utilização, sendo empregada na produção de pães, bebidas alcoólicas, etanol e muitos outros produtos.

Embora os agentes de fermentação alcoólica mais utilizados sejam as leveduras, principalmente as do gênero Saccharomyces, existem estudos para selecionar outros microrganismos capazes de desdobrar carboidratos na produção de álcool.

As bactérias alcoólicas da espécie Zymomonas mobilis apresentam atributos tecnológicos que potencializam o seu emprego na fermentação alcoólica em escala industrial, pois possui habilidades promissoras de transformar açúcares em etanol e gás carbônico, em condições comparáveis àquelas exigidas pelas leveduras. Possui uma produtividade em etanol a partir de glicose acima de $97 \%$ do valor teórico máximo (SPRENGER, 1996).

Gibbs e DeMoss (1954) demonstraram que essa bactéria utiliza, para o catabolismo anaeróbio desses carboidratos, uma modificação da via de
Entner-Duodoroff, podendo produzir mais do 1,9 mol de etanol por mol de glicose fermentada e pequena quantidade de lactato, de acordo com a seguinte reação:

1 glicose $\rightarrow 1,93$ etanol $+1,8 \mathrm{CO}_{2}+0,053$ lactato

As condições simples para seu crescimento, a alta tolerância ao açúcar e a resistência a altas concentrações de etanol tornaria o microrganismo um sério concorrente para as tradicionais leveduras, não fosse a pequena faixa de tipos de substrato, apesar de sua alta capacidade fermentativa. Zymomonas mobilis apresenta funções de cadeia de transporte de elétrons e bom crescimento em ambientes microaeróbicos, ocupando uma posição taxonômica claramente próxima dos organismos aeróbios Glucanobacter e Acetobacter. (SPRENGER, 1996).

Em 1984, Rogers et al. realizaram estudos comparativos entre a bactéria Zymomonas mobilis e a levedura Saccharomyces carlsbergensis em relação à produção de etanol. Nestes estudos, os autores observaram uma série de vantagens na fermentação com Zymomonas em relação à levedura. Esta bactéria apresenta aproximadamente o dobro de velocidade de crescimento, produz etanol numa velocidade seis a sete vezes maior e o fator de conversão de glicose em etanol é 5\% maior. Além disso, Zymomonas mobilis não requer controle adicional de oxigênio para manter sua viabilidade em altas concentrações de células (ROGERS et al, 1980). A capacidade de crescer rapidamente na ausência de oxigênio sugere seu uso em processos de fermentação contínuo para a produção comercial de etanol. Maiores detalhes desses resultados podem ser observados na Tabela 4. 
Tabela 4. Estudo comparativo entre a bactéria Zymomonas mobilis e a levedura Saccharomyces carlsbergensis utilizando um meio de cultura com uma concentração inicial de glicose de $100,0 \mathrm{~g} / \mathrm{L}$ com relação à produção de etanol.

\begin{tabular}{lcc}
\hline & Zymomonas mobilis & Saccharomyces carlsbergensis \\
\hline Tempo de processo $(\mathrm{h})$ & 2,51 & 5,64 \\
$\mu_{\mathrm{p}}\left(\mathrm{h}^{-1}\right)$ & 5,44 & 0,82 \\
$\mathrm{Y}_{\mathrm{x} / \mathrm{s}}$ & 0,028 & 0,043 \\
$\mathrm{Y}_{\mathrm{p} / \mathrm{s}}$ & 0,465 & 0,460 \\
\hline
\end{tabular}

Velocidade específica de produção de etanol $\left(\mu_{\mathrm{p}}\right)$, fator de conversão de glicose em células $\left(\mathrm{Y}_{\mathrm{x} / \mathrm{s}}\right)$ e em etanol $\left(\mathrm{Y}_{\mathrm{p} / \mathrm{s}}\right)$.

Fonte: Rogers et al. (1984).

Segundo Lyness e Doelle (1980), a fermentação quase quantitativa de glicose, frutose ou sacarose a etanol e dióxido de carbono é considerada uma característica importante do gênero Zymomonas. Quando glicose e frutose são utilizadas como fonte de carbono, é obtido um rendimento superior a $95 \%$ em relação ao rendimento teórico, pois a fermentação produz quase exclusivamente etanol e $\mathrm{CO}_{2}$. Quando sacarose, um substrato industrialmente disponível e de baixo custo, é utilizado, o rendimento de etanol representa $75-80 \%$ do valor teórico, devido à formação de subprodutos como levana e sorbitol.

\section{Tecnologia da produção de etanol por Zymomonas mobilis}

Em vários países têm sido realizados estudos de fermentação que incluem o uso de bactérias em vez de leveduras para reduzir o tempo de fermentação.

No Brasil, toda a produção industrial de álcool é realizada utilizando leveduras como microrganismo da fermentação e pouco se conhece de outros microrganismos que produzam álcool a nível industrial. Em virtude da situação de destaque em que se encontra o Brasil a nível mundial no setor energético, algumas instituições vêm selecionando microrganismos mais eficientes no processo de produção de álcool.

Vários autores consideram ser Zymomonas mobilis um excelente produtor de etanol, uma vez que, apresenta um ciclo de fermentação rápida e com elevada eficiência; apresenta tolerância a elevadas concentrações de glicose, de sacarose e de etanol; tolera $\mathrm{pH}$ entre 2,5 e 7,5 e apresenta bom rendimento em etanol. Esta produção de etanol é favorecida numa faixa de $\mathrm{pH}$ entre 4,5 e 7,0, pois o $\mathrm{pH}$ ideal para o crescimento da bactéria varia de acordo com a cepa utilizada (SWINGS; DE LEY, 1977; VIIKARI; GISLER, 1986; CALAZANS et al., 1989).

A temperatura ótima em meios contendo sacarose como fonte de carbono é de $35^{\circ} \mathrm{C}$, porém a $38^{\circ} \mathrm{C}$, ocorre uma diminuição de cerca de $26 \%$ do crescimento, e em temperaturas próximas de $40^{\circ} \mathrm{C}$, o crescimento é raro, dificultado ou inibindo a produção de etanol (LEE; WROBLE; ROSS, 1989).

Wisbeck et al. (1997), em trabalhos realizados com diferentes linhagens desta bactéria, relatam rendimentos em etanol superiores a 90\%. Estes autores descrevem, entretanto, que altas concentrações iniciais de glicose, em processo em batelada, levam a significativa redução da produtividade devido à inibição pelo substrato. Erzinger (1996) mostrou que este problema pode ser contornado pelo uso de fermentação em regime descontínuo alimentado.

Esses fatores são mostrados nas Tabelas 5 e 6 onde pode ser observado o efeito da concentração inicial de açúcar e do $\mathrm{pH}$ sobre os alguns parâmetros de fermentação para a produção de etanol por 4 linhagens de Zymomonas mobilis (ATCC 10988, ATCC 12526, NRRL B 4286 e IFO 13756). 
Tabela 5. Efeito do pH inicial sobre a produção de etanol por várias linhagens de Zymomonas mobilis.

\begin{tabular}{|c|c|c|c|c|c|}
\hline \multirow{3}{*}{$\mathrm{pH}$} & \multirow{3}{*}{$\begin{array}{c}\text { Parâmetros } \\
\text { fermentativos }\end{array}$} & \multicolumn{4}{|c|}{ Linhagens } \\
\hline & & ATCC & ATCC & NRRL B & IFO \\
\hline & & 10988 & 12526 & 4286 & 13756 \\
\hline \multirow{4}{*}{4,0} & $\mathrm{P}$ & $2-7$ & $2-2$ & $4-0$ & $3-5$ \\
\hline & $\mathrm{Su}$ & $74-4$ & $68-1$ & $85-6$ & $75-0$ \\
\hline & $\mathrm{g} / \mathrm{gs}$ & $0-18$ & $0-16$ & $0-23$ & $0-23$ \\
\hline & $\mathrm{E}$ & $26-37$ & $21-48$ & $39-06$ & $34-18$ \\
\hline \multirow{4}{*}{5,0} & $\mathrm{P}$ & $2-9$ & $3-2$ & $4-2$ & $4-4$ \\
\hline & $\mathrm{Su}$ & ND & ND & $87-5$ & $81-3$ \\
\hline & $\mathrm{g} / \mathrm{gs}$ & ND & ND & $0-24$ & $0-27$ \\
\hline & $\mathrm{E}$ & $28-32$ & $31-25$ & $41-02$ & $42-97$ \\
\hline \multirow{4}{*}{6,0} & $\mathrm{P}$ & $3-9$ & $4-0$ & $4-3$ & $4-7$ \\
\hline & $\mathrm{Su}$ & $80-6$ & $81-2$ & $87-5$ & $88-1$ \\
\hline & $\mathrm{g} / \mathrm{gs}$ & $0-24$ & $0-25$ & $0-25$ & $0-27$ \\
\hline & $\mathrm{E}$ & 38-09 & $39-06$ & 41-99 & $45-9$ \\
\hline \multirow{4}{*}{7,0} & $P$ & $6-6$ & $6-3$ & $5-2$ & $6-4$ \\
\hline & $\mathrm{Su}$ & $82-77$ & 79-0 & $88-1$ & $92-5$ \\
\hline & $\mathrm{g} / \mathrm{gs}$ & $0-40$ & $0-40$ & $0-30$ & $0-35$ \\
\hline & $\mathrm{E}$ & $64-45$ & $64-51$ & 50-29 & $62-5$ \\
\hline
\end{tabular}

$\mathrm{P}$ - produtividade de álcool \% (v/v); Su - substrato utilizado \% (v/v); g/gs - gramas de álcool produzido/g de substrato utilizado; E - porcentagem teórico de rendimento; ND - não determinado. Fonte: Gunasekaran, Karanakaran e Kasthuribai (1986).

Tabela 6. Efeito da concentração inicial de açúcar sobre a produção de etanol por várias linhagens de Zymomonas mobilis.

\begin{tabular}{lccccc}
\hline \multirow{2}{*}{$\begin{array}{c}\text { Açúcar } \\
\text { Inicial (\% } \\
\text { v/v) }\end{array}$} & Parâmetros & fermentativos & \multicolumn{5}{c}{ Linhagens } \\
\cline { 3 - 6 } & & ATCC & ATCC & NRRL B & IFO \\
& & 10988 & 12526 & 4286 & 13756 \\
\hline \multirow{2}{*}{15} & $\mathrm{P}$ & $6-6$ & $6-3$ & $5-1$ & $6-1$ \\
& $\mathrm{Su}$ & $82-77$ & $79-0$ & $88-0$ & $93-3$ \\
& $\mathrm{~g} / \mathrm{gs}$ & $0-43$ & $0-44$ & $0-31$ & $0-33$ \\
& $\mathrm{E}$ & $68-75$ & $65-63$ & $53-13$ & $63-54$ \\
\hline \multirow{3}{*}{20} & $\mathrm{P}$ & $5-9$ & $6-1$ & $10-15$ & $8-85$ \\
& $\mathrm{Su}$ & $73-0$ & $75-0$ & $89-0$ & $91-0$ \\
& $\mathrm{~g} / \mathrm{gs}$ & $0-32$ & $0-33$ & $0-46$ & $0-39$ \\
& $\mathrm{E}$ & $46-09$ & $47-65$ & $79-29$ & $69-14$ \\
\hline \multirow{2}{*}{25} & $\mathrm{P}$ & $5-2$ & $5-5$ & $7-9$ & $7-2$ \\
& $\mathrm{Su}$ & $76-0$ & $78-0$ & $84-8$ & $75-6$ \\
& $\mathrm{~g} / \mathrm{gs}$ & $0-22$ & $0-23$ & $0-30$ & $0-30$ \\
& $\mathrm{E}$ & $32-05$ & $34-38$ & $49-38$ & $45-0$ \\
\hline
\end{tabular}

$\mathrm{P}$ - produtividade de álcool \% (v/v); Su - substrato utilizado \% (v/v); g/gs - gramas de álcool produzido/ g de substrato utilizado; E - porcentagem teórico de rendimento.

Fonte: Gunasekaran, Karanakaran e Kasthuribai (1986). 
Em 1979, Rogers et al. estudaram a cinética de produção de etanol por Zymomonas mobilis ATCC 10988 e Saccharomyces carlsbergensis (uvarum), em altas concentrações de açúcar, e observaram que ambos os microrganismos fermentaram completamente $250 \mathrm{~g} / \mathrm{L}$ de glicose, produzindo etanol, em 30 a 40 horas, com concentração final de etanol superior a $100 \mathrm{~g} / \mathrm{L}$. Além disso, a concentração de biomassa de Zymomonas mobilis foi consideravelmente menor que a massa obtida pela levedura, indicando maior velocidade específica de consumo de açúcar e de produção de etanol para Zymomonas.

Lee, Wroble e Ross (1989) verificaram o comportamento de duas diferentes cepas de Zymomonas mobilis (ZM1 e ZM4) com relação à sensibilidade à temperatura de 25 a $40^{\circ} \mathrm{C}$ e observaram que, em temperaturas mais altas, os rendimentos da biomassa e de etanol decresciam. Porém, as velocidades específicas de crescimento, de consumo de substrato e de formação de produtos não foram afetados pela temperatura na faixa de $\mathrm{pH}$ estudada.

Torres (1987) estudou a influencia do tamanho do inóculo, da concentração inicial de glicose, do $\mathrm{pH}$ inicial e da temperatura, sobre a fermentação etanólica em batelada, por Zymomonas mobilis (cepa ZAP), bem como a produção de levana em meio de sacarose durante o processo fermentativo desenvolvido por esta cepa. A análise dos resultados demonstrou que o aumento do inóculo em meio de glicose provoca elevação do teor de etanol formado sem, contudo diminuir significativamente o tempo de fermentação, escolhendo-se o inóculo de 10\% (v/v) como o mais apropriado. A concentração de glicose superior a $156,0 \mathrm{~g} / \mathrm{L}$ provocou inibição do crescimento. A temperatura "ótima" para a produção em meio de glicose situou-se a $35^{\circ} \mathrm{C}$; observou que, também, que o aumento da temperatura, a partir de $35^{\circ} \mathrm{C}$, ocasionou uma diminuição da fase "lag". No meio de sacarose suplementado com $\left(\mathrm{NH}_{4}\right)_{2} \mathrm{SO}_{4}$, a produção de etanol foi inferior aquela apresentada em meio semelhante tendo uréia como fonte de nitrogênio. Em meios de sacarose, além de levana, deve-se formar algum outro subproduto que justifique os baixos valores de eficiência bioquímica apresentados.

Erzinger (1996) estudou, em regime descontínuo e descontínuo alimentado, a influência da concentração inicial de glicose e do etanol formado sobre a atividade da GFOR em células íntegras de Zymomonas mobilis ATCC 29191. A GFOR é a mais importante enzima envolvida na conversão de glicose e frutose em ácido glucônico e sorbitol, respectivamente. Neste estudo, o crescimento celular e a produção de etanol, foram também considerados. Adicionalmente, ensaios de biotransformação, para a produção de sorbitol e ácido glucônico, foram realizados. Com concentrações iniciais de glicose (G0) entre 40 e $100 \mathrm{~g} / \mathrm{L}$, foram medidas as máximas velocidades específicas de crescimento $(\mu \mathrm{X}, \mathrm{M}$ $\left.=0,48 \mathrm{~h}^{-1}\right)$. Acima desta faixa, a concentração de glicose inibiu, progressivamente, o crescimento de Z. mobilis. Com $\mathrm{G} 0=230 \mathrm{~g} / \mathrm{L}$, o valor de $\mu \mathrm{X}, \mathrm{M}$ foi de, apenas, $0,17 \mathrm{~h}^{-1}$. Com concentrações de etanol maiores que $35 \mathrm{~g} / \mathrm{L}$, observa-se uma diminuição da velocidade específica de crescimento $(\mu X)$, indicando um efeito inibidor deste produto sobre o crescimento celular. $O$ fator de conversão de glicose em células $(\mathrm{Yx} / \mathrm{s})$ máximo obtido foi de, aproximadamente, 0,042, com G0 até $100 \mathrm{~g} / \mathrm{L}$. Os valores de G0 maiores que $100 \mathrm{~g} / \mathrm{L}$ levaram, à redução de $\mathrm{Yx} / \mathrm{s}$. As máximas velocidades específicas de formação de etanol $(\mu E t, m)$ se mantiveram, aproximadamente, constantes entre 4,3 e $4,9 \mathrm{~h}^{-1}$, com G0 entre 40 e $210 \mathrm{~g} / \mathrm{L}$. O valor de $\mu \mathrm{Et}, \mathrm{m}\left(3,4 \mathrm{~h}^{-1}\right)$, entretanto, diminui com $\mathrm{G} 0=230$ $\mathrm{g} / \mathrm{L}$. Com relação à conversão em produto (YEt/S), foram obtidos valores, aproximadamente, constantes (YEt/S 0,49), até G0 de $150 \mathrm{~g} / \mathrm{L}$. Concentrações de iniciais de glicose maiores que $210 \mathrm{~g} / \mathrm{L}$ resultam em diminuição de Y Et/S. Tal como descrito por Zachariou e Scopes (1986) para a enzima livre, a atividade de GFOR (A) em células íntegras de $Z$. mobilis, mostrou ser dependente da concentração de glicose utilizada no cultivo da bactéria. Valores 
crescentes de atividade foram medidos até $\mathrm{G} 0=150$ $\mathrm{g} / \mathrm{L}$, condição na qual verificou-se o mais alto valor de A ( 12,5 U/g de células). Com $\mathrm{G} 0=230 \mathrm{~g} / \mathrm{L}, \mathrm{A}$ (3,6 U/L) foi drasticamente reduzido. As menores atividades de GFOR em células íntegras, com G0 >150 g/L, são decorrentes das concentrações elevadas de etanol alcançadas nestes casos (Ex.: $\mathrm{G} 0 \sim 210 \mathrm{~g} / \mathrm{L}, \mathrm{Et} \sim 94 \mathrm{~g} / \mathrm{L})$. Este efeito se deve, provavelmente, a alterações na interação enzima/ substrato, realacionadas com a formação de hopanóides, ácidos graxos produzidos por Z. mobilis na presença de altas concentrações intracelulares de etanol, cuja função é a impermeabilização da parede celular, a fim de proteger o microrganismo da ação solvente do etanol. O processo de biotransformação de glicose e frutose em ácido glucônico e sorbitol foi realizado utilizando células provenientes de diferentes condições de cultivo. Nos ensaios com células íntegras que apresentavam alta atividade em GFOR.

Ananthalakshmy e Gunasekaran (1999) produziram etanol com cepas de Zymomonas mobilis B4286 e dois mutantes (ZML1 e ZML2) obtidos através do tratamento com NTG (N-metil N'nitroso guanidina) e atingiram a produção máxima de etanol de 55,$1 ; 41,0$ e 44,2 $\mathrm{g} / \mathrm{L}$, respectivamente em 24 horas de fermentação a $30^{\circ} \mathrm{C}$ com concentração de sacarose de $150,0 \mathrm{~g} / \mathrm{L}$, e observaram que os mutantes ZML1 e ZML2 possuem taxas de produção de etanol significativamente menores que a cepa natural.

A fabricação de álcool nas unidades industriais realiza-se quase que exclusivamente através do processo de fermentação de batelada ou contínuo. Em ambos os casos as células encontram-se livremente dispersas no mosto a ser fermentado e após a fermentação estas são recuperadas através da centrifugação e retornam aos fermentadores, sendo etapa mais onerosa da fermentação. Diante deste fato, muitas pesquisas tem surgido com o propósito de eliminar do processo a centrifugação, através da aplicação de métodos de imobilização de células. Têm sido comumente utilizados em pesquisa substratos orgânicos, e recentemente inorgânicos, objetivando a produção de etanol. Em regimes de cultivo, o descontínuo e o contínuo utilizando Zymomonas mobilis, tem sido os mais estudados.

Os principais resultados em regime descontínuo encontrados na literatura, utilizando glicose como fonte de carbono, demonstram que neste tipo de processo, apesar da inibição causada pela concentração de substrato, altas concentrações de etanol podem ser obtidas. Segundo Rogers et al. (1982), o rendimento em etanol normalmente é maior que $95 \%$; o fator de conversão de glicose em biomassa varia de 0,015 a 0,050 , dependendo da concentração inicial de substrato e, a produtividade em torno de 5 a 7 g/L.h.

Estudos conduzidos usando duas técnicas para o processo contínuo: o reciclo de células (LAWFORD; ROUSSEAU, 2003) e o uso de células imobilizadas (AMIN; KHALAF; ALLAH, 1992) apresentaram excelentes resultados em laboratório, mas o custo é excessivamente elevado para o uso em processos industriais.

Lawford e Rousseau (2003) demonstraram que, em cultivo contínuo de Zymomonas mobilis linhagem ATCC 39676, à medida que os valores de velocidade de duplicação foram elevados de 0,05 a $0,20 \mathrm{~h}^{-1}$, os valores de biomassa e etanol também aumentaram.

Bekers et al. (1990) propuseram que o efeito inibidor do etanol era a causa de oscilações nos valores de biomassa, etanol e açúcar residual, pois o crescimento celular foi inibido em concentrações de etanol elevadas. Na medida que a concentração de etanol aumentou, houve diminuição da biomassa e aumento de substrato não consumido. Ainda, o crescimento celular e a produção de etanol voltaram a elevar-se após a diminuição da concentração de etanol para valores abaixo do nível inibidor. Essas observações também foram feitas no trabalho de Jobses et al. (1985), onde relataram que quando utilizada sacarose a $20 \%$, a concentração inibidora de etanol mostrou ser de $57,5 \mathrm{~g} / \mathrm{L}$ e, promoveu uma diminuição na biomassa de $6,45 \mathrm{~g} / \mathrm{L}$ para valores 
inferiores, bem como evidenciou também o aumento de sacarose residual.

Hermans (1992) trabalhando com fermentação em regime contínuo, com a linhagem Zymomonas mobilis ATCC 29191, utilizando concentrações de glicose $(150,0$ 170,0 e 200,0 g/L) obteve uma produtividade média de $4 \mathrm{~g} / \mathrm{L} . \mathrm{h}$, com rendimentos em etanol em torno de $98 \%$ e velocidade específica de produção de, aproximadamente, $1,1 \mathrm{~h}^{-1}$.

Costa et al. (2001) estudaram a fermentação contínua por Zymomonas mobilis ATCC 29191 em concentrações elevadas de sacarose e concluíram que a melhor condição para fermentação de sacarose a $10 \%(\mathrm{p} / \mathrm{v})$, mostrou ser na taxa de diluição de 0,21 $\mathrm{h}^{-1}$. Entretanto, para a fermentação de sacarose a 20\% $(\mathrm{p} / \mathrm{v})$, mesmo em taxa de diluição baixa, a cultura mostrou um período prolongado de oscilações, indicando dificuldade, senão impossibilidade, em atingir o estado estacionário.

Segundo Ingram e Buttke (1984), no Canadá, em Biohol, existe em funcionamento uma planta piloto para a produção de etanol utilizando serragem hidrolisada por via ácida e fermentação por Zymomonas mobilis e no Japão, Austrália e Nova Zelândia existem várias plantas-piloto operando em sistema contínuo utilizando diferentes linhagens de Zymomonas para a produção de etanol. Segundo esses autores, este microrganismo pode ser especialmente útil em países como o Brasil e a Índia, levando em consideração a característica termotolerante de Zymomonas mobilis.

Ernandes et al. (2007) estudaram diferentes condições de cultivo para produção de etanol por Zymomonas mobilis CCT 4494 através da variação das concentrações de sacarose $(5 ; 15$ e $25 \%)$ e de sais minerais $\left(\mathrm{KCl} ; \mathrm{K}_{2} \mathrm{SO}_{4} ; \mathrm{MgSO}_{4}\right.$ e $\left.\mathrm{CaCl}_{2}\right)$ e do $\mathrm{pH}$ inicial do meio de fermentação $(4,0 ; 6,0$ e 8,0), bem como, de diferentes temperaturas de incubação $\left(20,30\right.$ e $\left.40^{\circ} \mathrm{C}\right)$. As fermentações foram conduzidas a $200 \mathrm{rpm}$ e, após 24 horas, amostras do sobrenadante foram colhidas para a realização dos métodos analíticos. De acordo com o planejamento experimental $2^{7-0}$, o maior rendimento de etanol foi de $76,6 \mathrm{mg} / \mathrm{mL}$, a temperatura de $40^{\circ} \mathrm{C}$, quando o meio de cultura foi composto de $25 \%$ de sacarose e com $\mathrm{pH}$ inicial de 8,0 . O menor rendimento do produto correspondeu a $0,015 \mathrm{mg} /$ $\mathrm{mL}$ com o mesmo valor de $\mathrm{pH}$ inicial, porém com $5 \%$ de substrato e a temperatura de incubação de $20^{\circ} \mathrm{C}$. Além disso, os resultados indicaram que as diferentes concentrações de sais minerais testados influenciaram significativamente na produção de etanol.

\section{Produção de etanol utilizando substratos alternativos por Zymomonas mobilis}

Dada a importância dos carboidratos no metabolismo de qualquer via celular, não é por acaso que eles são a principal matéria-prima nas fermentações. Devem estar presentes compostos nitrogenados, além de prebióticos (fatores de crescimento), como vitaminas e coenzimas. Também é indispensável à presença de fósforo, sob a forma de fosfatos, o qual costuma ser adicionado aos meios, onde exerce ação tamponante ou inibidora de flutuações de pH (TANO; BUZATO, 2003).

Várias pesquisas estão sendo desenvolvidas para aumentar o rendimento de etanol juntamente com o emprego de técnicas mais econômicas de produção, recuperação e purificação, visando diminuir o custo total do processo. A nível experimental, utilizam-se substratos de baixo custo tais como sacarose, amido, amido hidrolisado, xarope de milho e melaços residuais da indústria açucareira.

Diversos subprodutos e matérias-primas da indústria de alimentos e/ou da agroindústria têm sido empregados para o crescimento de microrganismos, pela alta disponibilidade e baixo custo. Dentre estes, o caldo de cana e os melaços de cana-de-açúcar destacam-se com meio de cultivo nos processos fermentativos, em virtude do alto teor de açúcares, nitrogênio, vitaminas e sais minerais. 


\section{Caldo de cana e os melaços de cana-de- açúcar}

Gunasekaran, Karanakaran e Kasthuribai (1986). estudaram o efeito da adição de melaço de cana-deaçúcar em meios de cultivo para a produção de etanol, com diferentes linhagens Zymomonas mobilis. As linhagens ATCC 10988 e (3,05\% v/v) a NRRL B $4286(3,29 \% \mathrm{v} / \mathrm{v})$ mostraram máxima produtividade enquanto que IFO 13756, mínima produtividade (1,97\% v/v) (Tabela 7). A partir desses resultados, o desempenho de Zymomonas mobilis ATCC 10988 foi mais bem estudada em diferentes concentrações de açúcares presentes no melaço de cana-de-açúcar.
A Tabela 7 mostra que a máxima produção de etanol $(3,35 \% \mathrm{v} / \mathrm{v})$ foi com $15 \%$ de concentração inicial de açúcar e abaixo dessa concentração, a produção de etanol diminuiu significativamente. Em geral, os autores concluíram que a habilidade das linhagens de Zymomonas mobilis produzirem etanol a partir de melaços foi menor quando comparada com os outros substratos (meio sintético e cana-de-açúcar). Esta observação é semelhante com os resultados obtidos por Van Vuuran e Meyer (1982) onde relatam que isso poderia estar relacionado à presença de altas concentrações de íons $\mathrm{Mg}^{+2}$ e $\mathrm{K}^{+}$nos melaços (SKOTNICK et al., 1983).

Tabela 7. Efeito da concentração inicial de açúcar sobre a produção de etanol por várias linhagens de Zymomonas mobilis.

\begin{tabular}{ccc}
\hline Açúcar inicial & Produção de etanol & Rendimento teórico \\
\hline$(\% \mathrm{v} / \mathrm{v})$ & $(\% \mathrm{v} / \mathrm{v})$ & $(\%)$ \\
3 & $1-25$ & $65-1$ \\
5 & $2-0$ & $62-5$ \\
7 & $2-5$ & $55-8$ \\
10 & $3-05$ & $47-66$ \\
15 & $3-35$ & $34-9$ \\
\hline
\end{tabular}

Fonte: Gunasekaran, Karanakaran e Kasthuribai (1986).

Millichip e Doelle (1989), utilizaram sorgo moído a seco como substrato para Zymomonas produzir álcool em larga escala (586.000 litros), obtendo $13 \%(\mathrm{v} / \mathrm{v})$ de etanol. Além do sorgo, o milho e outras matérias-primas amiláceas foram testadas por Doelle, Millichip e Doelle (1989) para a fermentação em escala industrial (64.000 litros) de Zymomonas mobilis. Hebling (1995) investigou o efeito da adição de alguns compostos durante a fermentação de caldo de cana-de-açúcar por Zymomonas mobilis CP4, na expectativa de aumentar a produtividade alcoólica. Os aditivos testados foram: glicerol, Twenn 80, soro de queijo, peptona de caseína e sulfatos de amônio e magnésio. Os parâmetros cinéticos analisados foram: taxa especifica de crescimento, fator de produção de biomassa, fator de produção etanol e eficiência de conversão do substrato a etanol.

Alves (1993) buscou conhecimentos para o desenvolvimento futuro de novos processos biotecnológicos baseados na produção de etanol e que sejam economicamente rentáveis. Para isto, escolheu-se a bactéria Zymomonas mobilis como o principal agente microbiológico de transformação pois, este microorganismo apresenta uma serie de vantagens em relação a outros organismos produtores de etanol: 1) taxas de consumo de glicose e de produção de etanol elevadas; 2) formação quase que teórica de etanol; 3) formação de poucos produtos secundários do metabolismo e em quantidades insignificantes: 4) rendimento baixo de células; 5) rota metabólica dos fenômenos celulares 
importantes e a otimização do processo. Para isto, o autor desenvolveu um meio mínimo de cultura para Zymomonas mobilis NRRL B-806; descreveu-se o metabolismo de Zymomonas mobilis, apresentandose possíveis alternativas para a produção de outros produtos resultantes do catabolismo de açucares.

Duarte (1996) analisou o efeito da lecitina de soja e do destilado do desodorizado do óleo de soja (DDOS) na fermentação da sacarose e do caldo de cana por Saccharomyces cerevisiae e por Zymomonas mobilis CP4 em cultura de batelada. Com o açúcar redutor total em valor nominal de $15 \%(\mathrm{p} / \mathrm{v})$ e sem adição de suplemento lipídico, os açúcares não foram eficientemente utilizados e os resultados para Saccharomyces e Zymomonas, num meio contendo sacarose e caldo de cana foram, em média, respectivamente: eficiência de conversão (YE con.) 12,55 e 20,54\%; taxa especifica de crescimento máximo (Mmax.) 0,25 e 0,20 h ${ }^{-1}$. Com adição de lecitina de soja ou DDOS a $0,01 \%$ (v/v) em sacarose e caldo de cana-de-açúcar os resultados para Saccharomyces ou Zymomonas foram, em média, respectivamente: YE con. 13,69 e 26,15\%, enquanto que os valores de Mmax. foram: 0,24 e $0,22 \mathrm{~h}^{-1}$ e Yx/s: 0,025 e 0,012.

Ananthalakshmy e Gunasekaran (1999) que produziram etanol com cepas de Zymomonas mobilis B4286 e dois mutantes (ZML1 e ZML 2), obtidos através do tratamento com NTG (N-metil N'nitroso guanidina), e atingiram a produção máxima de etanol de 55,1; 41,0 e 44,2 g/L, respectivamente em 24 horas de fermentação a $30^{\circ} \mathrm{C}$ com concentração de sacarose de 150,0 g/L, e observaram que os mutantes ZML1 e ZML2 possuem taxas de produção de etanol significativamente menores que a cepa natural.

Cação (1999) realizou um estudo utilizando o planejamento fatorial de 2 níveis eqüidistantes de 3 variáveis $2^{3}$ para determinar as melhores condições de cultivo quanto a temperatura $\left(25\right.$ e $\left.35^{\circ} \mathrm{C}\right)$, agitação (0 e 150 rpm) e concentração de açúcares redutores totais no caldo de cana $(100,0$ e $200,0 \mathrm{~g} / \mathrm{L})$ e, 3 repetições no ponto central, onde a temperatura foi de $30^{\circ} \mathrm{C}$, agitação de $150 \mathrm{rpm}$ e concentração de açúcar redutor total no caldo de cana, usado como substrato para a produção de sorbitol e etanol, foi de 150,0 g/L. Observou-se que altas concentrações de açúcar no caldo de cana estimularam a produção de sorbitol e etanol. Os cultivos estáticos proporcionaram os melhores valores de produção de sorbitol porém, os melhores valores de etanol foram encontrados em cultivos com agitação de $150 \mathrm{rpm}$. Em relação as temperaturas testadas verificou que, estas, não foram uma variável significativa para a produção de sorbitol e etanol.

Tano e Buzato (2003) avaliaram a produção de etanol em caldo de cana fermentado por Zymomonas mobilis com alta concentração inicial de açúcar $(150,0 \mathrm{~g} / \mathrm{L})$, rico em sais minerais, adicionado de $5,0 \mathrm{~g}$ de extrato de levedura e incubado a $28^{\circ} \mathrm{C}$, durante 48 horas a $180 \mathrm{rpm}$, num $\mathrm{pH}$ de 5,4. Neste meio, observou-se a presença de etanol e foi constado que este reduziu a formação de mais etanol, porém não afetou a produção de levana nem o coeficiente de produtividade, quando relacionado à biomassa (g biomassa/g açúcar consumido). Estes mesmos pesquisadores observaram que alguns dos componentes presentes no caldo de cana-de-açúcar inibemocrescimento eafermentaçãopor Zymomonas mobilis. Os níveis relativamente elevados de alguns sais inorgânicos, especialmente cloreto de potássio e alguns íons como cálcio e magnésio, apresentam um efeito inibidor significativo na fermentação, além da competição de outros microrganismos que progrediram nele.

Borsari (2004) estudou as condições de produção de levana por Zymomonas mobilis CP4, através de delineamentos estatísticos variando a concentração e tipo de substrato, forma de cultivo, suplementação com ácido pantotênico, extrato de levedura, cloreto de sódio e a técnica de permeabilização celular. Inicialmente, foi aplicado um planejamento $2^{3}$ onde as variáveis foram: concentração de caldo de cana de açúcar e sacarose e tipo de fermentação. Um segundo planejamento $2^{2}$ foi usado para confirmar a 
importância do caldo de cana de açúcar. Um último delineamento fatorial fracionado $2^{4-1}$ foi utilizado para selecionar as variáveis: concentração de ácido pantotênico, cloreto de sódio e extrato de levedura e o crescimento celular. Os resultados indicam que o processo por batelada alimentada não melhorou a produção de levana. O máximo de levana obtido foi de 40,14 g/L $\mathrm{L}^{-1}$ em 150,0 g/L $\mathrm{L}^{-1}$ de sacarose. A adição de caldo de cana de açúcar não foi estatisticamente significativa para formação de levana. $\mathrm{O}$ caldo de cana de açúcar estimulou a produção de biomassa, sorbitol e etanol. Do delineamento $2^{4-1}$ os fatores analisados não foram estatisticamente significativos, para a biossíntese de levana, etanol e biomassa, sugerindo nos próximos estudos ampliar as faixas de variação estabelecida.

\section{Resíduos lignocelulósicos}

Os resíduos lignocelulósicos são os materiais orgânicos mais abundantes da biosfera, representando aproximadamente $50 \%$ da biomassa vegetal e podem ser usados como matéria-prima em processos industriais para a produção de alimentos, combustíveis insumos químicos, enzimas e bens de consumo diversos (KADAM; FORREST, JACOBSON, 2000).

O Brasil, com sua grande extensão territorial, apresenta alto potencial de exploração de recursos renováveis para a geração de diversos insumos. Um resíduo abundante no país e proveniente de material renovável é o bagaço de cana-de-açúcar, pois o Brasil é o maior produtor de cana-de-açúcar do mundo com uma produção estimada de aproximadamente de 390 milhões de toneladas no ano de 2004, segundo dados do Ministério da Agricultura (BRASIL, 2004).

Uma indústria sucroalcooleira produz cerca de $280 \mathrm{Kg}$ de bagaço por tonelada de cana moída (MOLINA et al., 1995) o que corresponde a uma produção de bagaço de aproximadamente 100 milhões de toneladas por ano. Grande parte deste resíduo, também considerado por muitos como subproduto, é utilizada pela própria usina como fonte de energia.

Embora o bagaço possa ser utilizado para geração de energia ou como suplemento em ração animal, ainda há um grande excedente que poder utilizado para produção de diversos bens à sociedade. Algumas alternativas para sua utilização como matéria-prima são a produção de etanol, hidroximetilfurfural, papel e celulose, revestimentos acústicos, madeira prensada, álcool, alcalóides, enzimas e xilitol (CUNHA et al., 2005).

Segundo Takahashi (1998), o etanol pode ser produzido a partir de resíduos lignocelulósicos. A hidrólise destes resíduos proporcionam uma mistura de pentoses e hexoses, e a conversão completa destes açúcares em etanol é fundamental para que o preço do etanol produzido seja competitivo com o da gasolina. Escherichia coli KO11, possuindo os genes PDC (piruvato descarboxilase) e ADH (álcool desidrogenase) de Zymomonas mobilis inseridos em seu cromossomo, mostrou-se capaz de fermentar eficientemente pentoses e hexoses a etanol, em condições anaeróbicas. Em meio LB (Luria-Bertani), contendo extrato de levedura, peptona e $\mathrm{NaCl}$, acrescido de $50 \mathrm{~g} / \mathrm{L}$ de glicose, a bactéria produziu $21,1 \mathrm{~g} / \mathrm{L}$ de etanol, equivalente a $82,2 \%$ do rendimento teórico máximo. Em meio $\mathrm{LB}$ acrescido de $40 \mathrm{~g} / \mathrm{L}$ de xilose, produziu 16,3 g/L de etanol, o que corresponde a uma eficiência de conversão de 80,2\%. Em uma mistura de $10 \mathrm{~g} / \mathrm{L}$ de glicose e $40 \mathrm{~g} / \mathrm{L}$ de xilose, a bactéria recombinante produziu 24,5 g/L de etanol, com eficiência de 96,4\%. No hidrolisado de bagaço de cana-de-açúcar, os açúcares foram completamente consumidos em 48 horas e a eficiência de conversão foi de $95 \%$. O meio "corn steep powder"(CSP), na concentração de $12,5 \mathrm{~g} / \mathrm{L}$, substituiu eficientemente o meio LB como fonte de nutrientes. $\mathrm{O}$ acetato, potencial inibidor do crescimento e do metabolismo de $E$. coli, está presente nos hidrolisados hemicelulósicos numa faixa de concentrações de 2,0 a 15,0 g/L. E. coli KO11 mostrou-se extremamente tolerante ao 
acetato. Em meio LB acrescido de glicose ou xilose mais acetato, foi observado que concentrações de 2,0 a $12,0 \mathrm{~g} / \mathrm{L}$ não afetaram o desempenho fermentativo da bactéria. No entanto, foi verificado que todas as concentrações de acetato testadas (2,0 a 12,0 g/L) tiveram um efeito inibitório sobre o crescimento bacteriano. Nos valores de $\mathrm{pH}$ mais baixos $(5,5$ e 6,0$)$, a inibição foi exacerbada devido à maior concentração da forma protonada do ácido acético.

\section{Agradecimentos}

Agradecimentos a Fundação de Amparo a Pesquisa (FAPESP) pelo auxílio recebido para a elaboração do trabalho.

\section{Referências}

ALVES, T. L. M. Estudo da produção de etanol por Zymomonas mobilis. 1993. Dissertação (Doutorado em Engenharia Química) - Universidade Federal do Rio de Janeiro, Rio de Janeiro.

AMIN, G.; KHALAF ALLAH, A. M. By products formed during direct conversion of sugar beets to ethanol by Zymomonas mobilis in conventional submerged and solid-state fermentation. Biotechnology Letters, Kew, England ,v. 14, p. 1187-1192, 1992.

ANANTHALAKSHMY, V. K.; GUNASEKARAN, P. Isolation and chacterization of mutants from levanproducing Zymomonas mobilis. Journal of Bioscience and Bioengineering, Osaka, v. 87, p. 214-217, 1999.

BEKERS, M.; SHVINKA, J.; PANKOVA, L.; LAIVENIEKS, M.; MEZBARDE, I. Simultaneous sucrose bioconversion into ethanol and levan by Zymomonas mobilis. Applied Biochemystry and Biotechnology, Berlin, v. 24, p. 265-274, 1990.

BELAICH, J. P.; SENEZ, J. C. Influence of aeration and of penthothenate on growth of Zymomonas mobilis. Journal of Bacteriology, Washington, v. 89, p. 11951200, 1965.

BORSARI, R. R. J. Avaliação das diferentes condições de cultivo para a produção de levana por CP4. 2004. Dissertação (Mestrado em Biotecnologia) - Universidade Estadual de Londrina, Londrina.

BRASIL. Ministério da Agricultura. Plano Agrícola e Pecuário 2004/2005. Disponível em: <www.agricultura. gov.br>. Acesso em: 29 mar. 2004.
CAÇÃO, S. M. B. Fermentação de caldo de cana-deaçúcar por Zymomonas mobilis ATCC 29191 para produção de etanol e sorbitol. 1999. Dissertação (Mestrado em Ciências de Alimentos) - Universidade Estadual de Londrina, Londrina.

CALAZANS, G. M. T.; RIOS, E. M.; MORAIS, J. O. F. D.; SOUZA, M. D. F. V. Q.; MARCAL, M. D. C. R.; LEIX, S.; LOPES, C. E. The levan and ethanol production by Zymomonas mobilis strain ZAP in sucrose media. Arquivos de Biologia e Tecnologia, Curitiba, v. 32, p. 631, 1989.

CARR, J. G.; PASSMORE, S. M. Discovery of the "cider-sickness" bacterium Zymomonas anaerobia in apple pulp. Journal of the Institute of Brawing, London, v. 77, p. 462-466, 1971.

CARR, J. G. Genus Zymomonas. In: _. Bergey`s: Manual of determinative bacteriology. 8. ed. Baltimore: Williams \& Wilkins, 1974, p. 8-21.

COSTA, F. H. N.; BUZATO, J. B.; CELLIGOI, M. A. P. C.; TANO, M. S. Fermentação contínua por Zymomonas mobilis ATCC 29191 em concentrações elevadas de sacarose. Semina: Ciências Exatas e Naturais, Londrina, v. 3, p. 201-207, 2001.

CROMIE, S.; DOELLE, H. W. Relationship between maintenance energy requirements, mineral salts and efficincy of glucose to ethanol conversion by Zymomonas mobilis. Biotecnology Leters, Kew, England, v. 2, p. 357$362,1980$.

CUNHA, M. A. A.; SILVA, S. S.; CARVALHO, W.; SANTOS, J. C. Uso de células imobilizadas em gel de PVA: uma nova estratégia para produção biotecnológica de xilitol a partir de bagaço de cana-de-açúcar. Semina: Ciências Agrárias, Londrina, v. 26, p. 61-70, 2005.

DADDS, M. J.; MARTIN, P. A. The genus Zymomonas a review. Journal of the Institute of Brewing, London, v. 79, p. 386-391, 1973.

DOELLE, H. W.; KIRK, L.; CRITTENDEN, R.; TOH, H. Zymomonas mobilis - Science an industrial application. Critical Reviews in Biotechnology, London, v. 13, p. 5798, 1993.

DOELLE, M. B.; MILLICHIP, R. J.; DOELLE, H. W. Production of ethanol from corn using inoculum cacading of Zymomonas mobilis. Process Biochemistry, London, v. 15, p. 137-140, 1989.

DUARTE, J. C. Fermentação alcoólica por Zymomonas mobilis CP4 ou por Saccharomyces cerevisae em caldo de cana-de-açúcar com ou sem suplementação lipidica. Arquivos de Biologia e Tecnologia, Curitiba, v. 39, n. 2, p. 285-293, 1996. 
ERNANDES, F. M. P. G. Produção de levana por Bacillus subtilis e Zymomonas mobilis utilizando três meios de cultura sintéticos e um alternativo (caldo de cana-deaçúcar). 2006. Dissertação (Mestrado em Engenharia e Ciências de Alimentos) - Instituto de Biociências, Letras e Ciências Exatas, Universidade Estadual Paulista, São José do Rio Preto.

ERNANDES, F. M. P. G.; BOFO, D. C. S.; COVIZZI, L. G.; JUSTO, A. R. G.; BOSCOLO, M.; GARCIACRUZ, C. H. Otimização das condições de cultivo para produção de etanol por Zymomonas mobilis CCT 4494. In: SIMPÓSIO LATINO AMERICANO DE CIÊNCIA DE ALIMENTOS FACULDADE DE ENGENHARIA DE ALIMENTOS - FEA, 7., 2007, Campinas. Anais... Campinas - SP: Ed. da UNICAMP, 2007. p. cd-room

ERNANDES, F. M. P. G.; GARCIA-CRUZ, C. H. Levana bacteriana: aspectos tecnológicos, características e produção. Semina: Ciências Agrárias, Londrina, v. 26, p. 15-19, 2005.

ERZINGER, G. S. Influência da concentração de glicose e etanol sobre a atividade de glicose-frutose oxidorredutase em Zymomonas mobilis ATCC 29191. 1996. Dissertação (Mestrado) - Escola Politécnica, Universidade de São Paulo, São Paulo.

FALCÃO DE MORAIS, J. O. Isolamento de Zymomonas mobilis em mostos de caldo de cana de fermentações industriais. Revista de Microbiologia, São Paulo, v. 14, p. 6-10, 1983.

.Zymomonas mobilis e seu possível emprego como agente de fermentação alcoólica. Revista do Instituto de Antibióticos, Recife, v. 21, p. 169-182, 1983.

FALCÃO DE MORAIS, J. O.; RIOS, E. M. M. M.; CALAZANS, G. M. T.; LOPES, C. E. Zymomonas mobilis research in the Pernambuco Federal University. Journal of Biotechnology, Amsterdan, v. 31, p. 75-91, 1993.

GARCIA-CRUZ, C. H. Produção de polissacarídeos bacterianos. 1997. Dissertação (Título de Livre Docente) - Instituto de Biociências, Letras e Ciências Exatas, Universidade Estadual Paulista, São José do Rio Preto.

GIBBS, M.; DEMOSS, R. D. Anaerobic dissimilation of C14, lapelled glucose and fructose by Pseudomonas lindneri. Journal of Biology Chemistry, Bethesda, v. 207, p. 689-694, 1954.

GONÇALVES DE LIMA, O.; ARAÚJO, J. M.; SCHUMACHER, I. E.; SILVA, E. C. Estudos de microrganismos antagonistas presentes nas bebidas fermentadas usadas pelo povo do Recife. Revista do Instituto de Antibióticos, Recife, v. 10, p. 3-15, 1970.
GUNASEKARN, P.; KARUNAKARAN, T; KASTHURIBAI, M. Fermentation pattern of Zymomonas mobilis strains on different substrates - a comparative study. Journal Bioscience, India, v. 10, p. 181-186, 1986.

HEBLING, R. M. U. Efeito de aditivos sobre a fermentação alcoólica por Zymomonas mobilis. 1995. Dissertação (Mestrado em Microbiologia Aplicada) Universidade Estadual Paulista, Rio Claro.

HERMANS, M. Untersuchungen zum einflu $\beta$ von ethanol auf den stoffwechsel von Zymomonas mobilis. Julich: Institut fur Biotechnologie. Forschungszentrum Julich Gmbh, p. 1-117, 1992.

INGRAM, L. O.; BUTTKE, T. M. Effects of alcohols on microrganismos. Advance Microbiology and Physiology, Bethesda, v. 25, p. 256-300, 1984.

ISHIZAKI, A.; TRIPETCHKUL, S.; TONOKAWA, M.; SHI, Z.; SHIMIZU, K. pH-mediated control methods for continuous ethanol fermentation using Zymomonas mobilis. Journal of Fermentation and Bioengineering, Japan, v. 77, p. 541-547, 1994.

JEREZ, M. C. D. Estudo comparativo de diferentes métodos e condições de fermentação de melaço de canade-açúcar por Zymomonas mobilis. 1993. Dissertação (Doutorado em Ciência de Alimentos) - Universidade Estadual de Campinas, Campinas.

JOBSES, I. M. L.; EGBERTS, G. T. C.; BAAEN, A.; ROELS, J. A. Mathematical modelling of growth and substrate conversion of Zymomonas mobilis at 30 and $35^{\circ} \mathrm{C}$. Biotechnology and Bioengineering, New York, v. 27, p. 984-995, 1985.

KADAM, K. L.; FORREST, L. H.; JACOBSON, W. A. Rice straw as a lignocellulosec resource: collection, processing, transportation, and environmental aspects. Biomass and Bioenergy, Oxford, v. 18, p. 369-389, 2000.

LAWFORD, H. G.; ROUSSEAU, J. D. Cellulosic fuel ethanol: alterantive fermentation process designs with wild-type and recombinant Zymomonas mobilis. Applied Biochemistry and Biotechnology, Clifton, USA, v. 106, p. 457-470, 2003.

LEE, S.; WROBLE, M. H.; ROSS, J. T. L-asparaginase from Erwinia carotovora: an improved recovery and purification process using affinity chromatography. Applied Biochemistry and Biotechnology, Clifton, USA, v. 22, p. 223-245, 1989.

LEHNIGER, A. L. Princípios de bioquímica. São Paulo: Edgard Bluncher, 2002. 
LOOS, H.; KRÄMER, R.; SAHM, H.; SPRENGER, G. A. Sorbitol promotes growth of Zymomonas mobilis in environments with high concentrations of sugar: Evidence for a pysiological function of glucosefructose oxidoreductase in osmoprotection. Journal of Bacteriology, Washington, v. 176, p. 7688-7693, 1994.

LYNESS, E. W.; DOELLE, H. W. Effect of temperature on sucrose to ethanol conversion by Zymomonas mobilis strains. Biotechnology Letters, Kew, England, v. 2, p. 549-554, 1980.

MILLICHIP, R.; DOELLE, H. M. Large-scale production from milo (Sorghum) using Zymomonas mobilis. Process Biochemistry, London, v. 8, p. 141-145, 1989.

MILLIS, N. F. A study of the cider-sickness Bacillus: a new variety of Zymomonas anaerobia. Journal of General Microbiology, London, v. 15, p. 521-528, 1956.

MOLINA, J. W. F.; RIPOLI, T. C.; GERALDI, R. N.; AMARAL, J. R. Aspectos econômicos e operacionais do enfardamento de resíduo de colheita de cana-de-açúcar para aproveitamento energético. STA-Açúcar, Álcool e Subprodutos, Piracicaba, v. 13, p. 28-31, 1995.

ROGERS, P. L.; LEE, K. J.; SKOTNICKI, M. L.; TRIBE, D. E. Ethanol production by Zymomonas mobilis. Advances in Biochemical Engineering, New York, v. 23, p. 37-84, 1982.

ROGERS, P. L.; SKOTNICHI, M. L.; LEE, K. J.; LEE, J. H. Recent developments in the Zymomonas process for ethanol production. Biotechnology, Frankfurt, v. 1, p. 273-288, 1984.

ROGERS, P. L.; PHIL, D.; LEE, K. J.; TRIBE, D. E. High productivity ethanol fermentations with Zymomonas mobilis. Process Biochemistry, London, v. 15, p. 7-11, 1980.

SKOTNICKI, M. L.; WARR, R. G.; GOODMAN, A. E.; LEE, K. J.; ROGERS, P. L. High productivity alcohol fermentations using Zymomonas mobilis. Biochemical Society Symposia,London, v. 48, p. 53-86, 1983.

SPRENGER, G. A. Carbohydate metabolism in Zymomonas mobilis: a catabolic highway with some scenic routes. FEMS Microbiology Letters, Amsterdam, v. 145, p. 301-307, 1996.
SWINGS, J.; DE LEY, J. The biology of Zymomonas. Bacteriological Reviews, Baltimore, v. 41, p. 1-46, 1977.

TAKAHASHI, C. M. Produção de etanol por Escherichia coli geneticamente modificada: influência de fatores nutricionais. 1998. Dissertação (Mestrado em Ciências Biomédicas) - Universidade de São Paulo, São Paulo.

TANO, M. S.; BUZATO, J. B. Effect of the presence of initial ethanol on ethanol production in sugar cane juice fermented by Zymomonas mobilis. Brazilian Journal of Microbiology, São Paulo, v. 34, p. 242-244, 2003.

TOMA, M. M.; KALNENIEKS, U.; BERZINS, A.; VIGANTS, A.; RIKMANIS, M.; VIESTURS, U. The effect of mixing on glucose fermentation by Zymomonas mobilis continuous culture. Process Biochemistry, London, v. 38, p. 1347-1350, 2003.

TORRES,E.F.;BARATTI,J.The effect of $\mathrm{pH}$, temperature and sucrose concentration on high productivity continuous ethanol fermentation using Zymomonas mobilis. Applied Microbiology Biotechnology, Berlin, v. 27, p. 27-121, 1987.

VAN VUUREN, M. J. J.; MEYER, L. Production of ethanol from sugar cane molasses. Biotecnology Letters, Kew, England, v. 4, p. 253-256, 1982.

VIIKARI, L.; GISLER, R. By-products in the fermentation of sucrose by different Zymomonas strains. Applied Microbiology and Biotechnology, Berlin, v. 23, p. 240-244, 1986.

WISBECK, E.; SILVEIRA, M. M.; NINOW, J.; JONAS, R. Evalulation of the flocculent strain Zymomonas mobilis Zl-81 for the production of sorbitol and gluconic acid. Journal Basic of Microbiology, Berlin, v. 6, p. 445449, 1997.

YUN, J. W. Fructooligosaccharides: Occurrence, preparation and application. Enzyme and Microbial Technology, Woburn, v. 19, n. 2, p. 107-117, 1996.

ZACHARIOU, M; SCOPES, P.K. Glucose-fructose oxidoreductase, a new enzymes isolated from Zymomonas mobilis that is responsible for sorbitol production. Journal of Bacteriology, Washington, v.167, p.863-869, 1986. 